\title{
Identifying Efficient Dairy Producers Using Data Envelopment Analysis
}

\author{
J. R. Stokes, ${ }^{* 1}$ P. R. Tozer, $†$ and J. Hyde ${ }^{\star}$ \\ *Department of Agricultural Economics and Rural Sociology, The Pennsylvania State University, University Park 16802 \\ †Department of Agriculture and Food Western Australia, Geraldton, 6530, Western Australia
}

\begin{abstract}
The objective of this research was to calculate the efficiency of a group of Pennsylvania dairy farms to determine factors that contributed to efficiency in production and business management. Data envelopment analysis (DEA) was used to estimate the efficiency. Two models were developed to measure the efficient use of physical (land, cows, and labor) inputs to produce physical (milk and butterfat) outputs, and the use of physical and economic (debt capital) inputs to produce physical and economic (income) outputs. The results showed that about $29 \%$ of the producers in our sample were DEAefficient and demonstrated that there was no combination of inputs used by efficient producers that was best. In addition, the method of analysis illustrated the benefits of DEA in that it is possible to identify the set of efficient producers that inefficient producers can benchmark to in an effort to achieve similar levels of efficiency. Finally, the analysis demonstrated that producers should not benchmark to the highest level of production, but rather should combine resources in land, labor, cows, and debt capital to achieve an efficient level of production, which indeed may be less than the maximum production level of the group.
\end{abstract}

Key words: efficiency, dairy, production, data envelopment analysis

\section{INTRODUCTION}

Dairy producers combine multiple inputs such as land, labor, cows, feed, capital equipment, and managerial ability to produce multiple outputs such as the milk and milk components fat and protein. Yet, as the costs of inputs increase and prices for milk and milk products remain steady or decline, producers are required to become more efficient in combining these inputs to produce milk to remain profitable. The challenge for producers is to identify the most efficient combination of inputs to produce outputs. One method of determining

Received September 14, 2006.

Accepted December 21, 2006.

${ }^{1}$ Corresponding author: jstokes@psu.edu best practice is to use benchmarks, such as milk per cow, milk sold per worker, or costs per unit of milk produced. But these measures are only partial measures of efficiency. The problem with these partial measures is that when producers attempt to address one benchmark, they affect others, directly or indirectly (Fraser and Cordina, 1999). Also, benchmarks concentrate on differences in average production between farms in the benchmark group, rather than on optimizing the farm-specific production in the benchmark group (Fraser and Hone, 2001).

An alternative to partial efficiency measures is to use a measure of the efficiency of the farming system as a whole. Techniques such as data envelopment analysis (DEA) or stochastic frontier analysis are capable of measuring whole-farm system efficiency (Jaforullah and Premachandra, 2004). Data envelopment analysis is a nonparametric method of calculating the efficiency of individual decision-making units (DMU) such as dairy farms for performance measurement, analysis, and benchmarking (Weersink et al., 1990; Tauer, 1993). This method of analysis has many attributes to assist producers and advisors in determining the best allocation of farm business resources and the scale of operation for that business to ensure the system is producing at an efficient level (Fraser and Cordina, 1999). Stochastic frontier analysis (SFA) is a parametric method of estimating efficiency and further differs from DEA in that an error term is included in the model (BravoUreta and Rieger, 1991). Because of the parametric method used in SFA and the ability of DEA to identify benchmarks, DEA is preferred in this research.

Data envelopment analysis compares the levels of inputs and outputs for a given DMU against all other DMU in the data set to determine which DMU are producing at efficient levels relative to the entire group. The method assigns an efficiency score ranging from 0 to 1 to each DMU in the analysis group and can be used to determine how inputs and outputs should be adjusted to obtain DEA efficiency. Data envelopment analysis provides specific information about which efficient DMU the inefficient DMU should benchmark to (Jaforullah and Whiteman, 1999). Unlike regression, DEA allows for multiple outputs (dependent variables) 


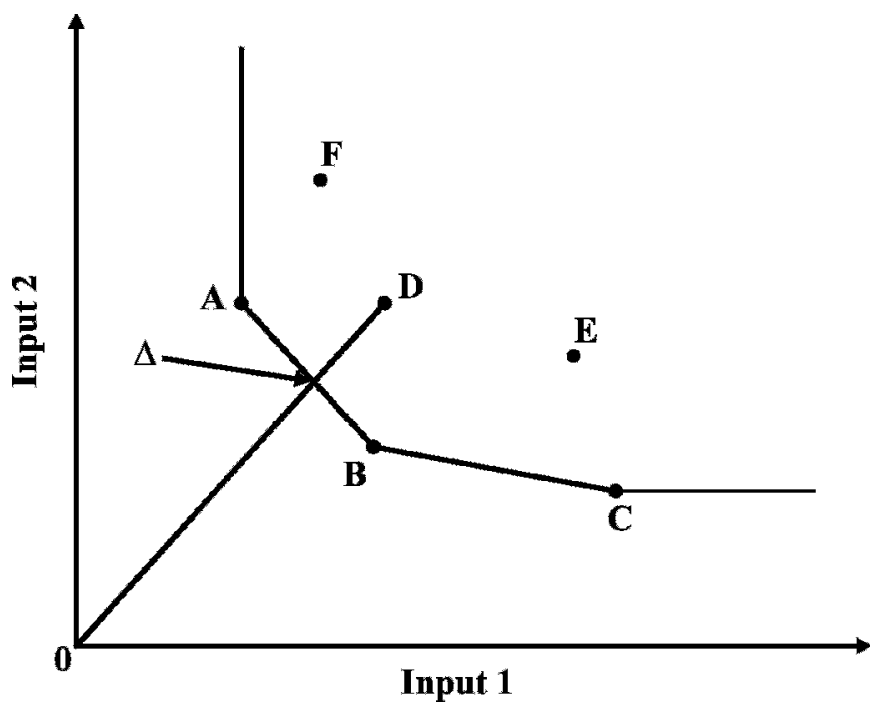

Figure 1. Example data envelopment analysis efficient frontier for 2 inputs and 1 output with 6 decision-making units, A to F. Points A through $\mathrm{F}$ represent combinations of inputs 1 and 2 that result in 1 unit of output being produced. Because inputs are costly, combinations $\mathrm{A}, \mathrm{B}$, and $\mathrm{C}$ form the efficient frontier, whereas combinations E, F, and D are inefficient. Delta represents an efficient input combination, with $0 \rightarrow \Delta$ being a measure of how inefficient input combination $\mathrm{D}$ is.

in a single equation and is a distribution-free (i.e., nonparametric) technique.

Tauer (1993) and Weersink et al. (1990) utilized DEA to estimate the technical and allocative efficiency of dairy farms in New York State and Ontario, respectively, but did not examine the efficiency of each input or DMU individually. Tauer (2001), using a frontier analysis model of the efficiency of New York State dairy farms, concluded that further study was needed to identify cost-efficient production methods for efficient producers and how other producers could implement these production methods. The primary objective of this research was to calculate the DEA efficiency of a group of Pennsylvania dairy farms to help determine factors that contribute to efficiency in production and business management. Two DEA models were developed to measure the efficient use of physical inputs to produce physical outputs and the use of physical and economic inputs to produce physical and economic outputs.

\section{MATERIALS AND METHODS}

\section{DEA Efficiency}

The basic concept behind DEA efficiency can best be described with a simple example. As noted above, the entities under investigation with DEA are referred to as decision-making units or DMU. Depicted in Figure 1 is a simple example of $6 \mathrm{DMU}$ each using 2 inputs to produce a single output. The input values were assumed "normalized" so that each DMU's use of the 2 inputs results in 1 unit of the output being produced.

As shown, DMU A, B, and C are DEA-efficient in the sense that they use the least amount of costly inputs to produce 1 unit of output, albeit with different combinations of the inputs. The line segments connecting points $\mathrm{A}, \mathrm{B}$, and $\mathrm{C}$ are collectively referred to as the "efficient frontier" in the DEA literature. Because inputs are costly, the efficient frontier represents all leastcost combinations of inputs capable of producing the common output level.

The remaining 3 DMU in Figure 1 are DEA-inefficient because they are using more of each input (or a convex combination of inputs) than DMU A, B, and C to produce 1 unit of output. For example, DMU D could reduce its use of either or both inputs to move back to the efficient frontier. Reducing the use of input 1 (or input 2) moves DMU D to the left (or down) toward DMU A (or DMU B) and closer to the frontier. Reducing the use of both inputs will move DMU D back to the frontier somewhere along the line segment $\mathrm{AB}$ (Cooper et al., 2000).

An estimate of relative efficiency can be obtained for each DMU by projecting a ray from the origin to each DMU point like $\mathrm{D}$. An estimate of efficiency is then $\theta=$ $0 \Delta / 0 \mathrm{D}$ ( $\theta$ is the ratio of the distances from the origin, 0 , to point $\Delta$ and the origin, 0 , to point $\mathrm{D}$ ), which is always less than 1 for an inefficient DMU and equal to 1 for frontier (efficient) DMU. The efficiency estimate indicates the percentage by which both inputs should be reduced to efficiently produce the 1 unit of output (Cooper et al., 2000). For example, $\theta=0.75$ would imply that the use of each input should be reduced by $25 \%$ (or to $75 \%$ of current input levels) to achieve DEAefficient production.

It is important to point out that the DEA technique is nonstochastic. This means that either the data are observed without error or the relationship between inputs and outputs is deterministic. Although this assumption is relatively stringent, it is counterbalanced somewhat because no assumptions on the nature of the uncertainty (i.e., the errors) have to be made to use the technique. Stochastic frontier analysis was designed to address this specific shortcoming of DEA, although, in doing so, SFA relies on very specific distributional assumptions for the error and functional form for the relationship between inputs and outputs. If the distributional assumptions or the functional form are misspecified, it is likely that the results would be no more credible than those associated with a (deterministic) DEA specification. 


\section{The Charnes, Cooper, Rhodes DEA Model}

The DEA model implemented to examine Pennsylvania dairy farm efficiency is the Charnes, Cooper, Rhodes (CCR; Charnes et al., 1978) model with an input orientation. [Although Charnes et al. (1978) are credited with the first empirical application of DEA, research going back to at least Seitz (1971) is related.] This model embodies the basic ideas discussed in the previous section. The input orientation feature simply means that DEA inefficiency is estimated with respect to the inputs as opposed to the outputs. With an output orientation, inefficiencies are stated in terms of outputs rather than inputs, so taking an output orientation will not change the results.

The CCR model is implemented as a linear program expressed for each DMU $j$ as

$$
\begin{gathered}
\min \theta_{j} \\
\theta_{j} x_{j m} \geq \sum_{k=1}^{K} x_{k m} \lambda_{j k} \quad \text { for all } m \\
\sum_{k=1}^{K} y_{k i} \lambda_{j k} \geq y_{j i} \quad \text { for all } i \\
\lambda_{j k}, \theta_{j} \geq 0,
\end{gathered}
$$

where $m$ indexes inputs so that $x_{j m}$ is the amount of input $m$ used by DMU $j$ and $x_{k m}$ is the amount of input $m$ used by each of the other $K$ DMU. Also, in Eq. 1, $i$ indexes outputs so that $y_{j i}$ represents the amount of output $i$ produced by DMU $j$ and $y_{k i}$ is the amount of output $i$ produced by each of the other $K$ DMU. Notice that the linear program above is solved once for each $\mathrm{DMU}$, so that efficiency is gauged for each DMU $j$ relative to each of the other $K \mathrm{DMU}$ in the sample.

The objective of the linear program is to find an optimal set of weights denoted by $\lambda_{j k}$ that satisfy the $m \times$ $i$ constraints and give an efficiency score denoted by 0 $\leq \theta_{j} \leq 1$. The magnitude of the weights gives information about relevant benchmarks for each inefficient DMU. That is, the weights taking on positive values form the set of potential benchmarks for the inefficient DMU in question. Furthermore, the largest weight is the most appropriate efficient DMU for the inefficient DMU to benchmark. This is an important point in that it is the DEA model solution that determines the appropriate benchmarks for the inefficient DMU rather than an exogenous source such as an average.

\section{DEA Inputs, Outputs, and Data}

Decision makers have 2 sets of inputs, controllable and noncontrollable (Jaforullah and Whiteman, 1999). Controllable inputs are those that the manager can control, such as hectares to farm, barn type, breed type, labor use, number of cows, and milking system. Noncontrollable inputs are those over which the manager has no control such as the weather and the prices for inputs and outputs. Also, when comparing efficiencies across systems it is necessary to ensure that production technology is homogeneous across DMU. If different technologies are compared, differences in efficiencies may be due to technology and not to the mix of inputs used. Differences in efficiencies between DMU are the result of variables not included in the DEA model such as production and business management ability. Hence, when constructing these models it is important to capture variables that have the most impact on the efficiency of the system (Jaforullah and Whiteman, 1999). Other factors that may affect the efficiency of the system include producers' goals and other nonmeasurable factors. The region of production can affect efficiency scores across systems; however, in this case all producers were located in Pennsylvania to maintain the homogeneity of the data set.

Although a dairy farm is designed to produce a single output, namely milk, this output represents a joint or multiproduct output because both milk and fat contribute to the revenue-generating activities of the farm business. Therefore, perhaps the most obvious outputs for a dairy farm are milk and butterfat production. All else being equal, higher milk production is more desirable as is higher butterfat production. Protein and milk solids contribute to the income of dairy producers and would have similar effects on income as butterfat and milk yield; however, in the data set used this information was not available.

The number of cows, acres farmed, and labor used form a set of important inputs for determining how much milk and butterfat a dairy farm produces. More cows produce more milk, so the number of dairy cows is a critical, if not obvious, input affecting milk production. Similarly, the more hectares a dairy farm uses, the more milk production that is anticipated. Lastly, more labor would generally be associated with more milk production and labor full-time equivalents (FTE) are used as the relevant input variable. Therefore, a representation of the input/output relationship is simply:

$$
y(\text { milk, butterfat })=x(\text { land }, \text { labor, cows }),
$$

where $y$ is a general output function with milk and butterfat production arguments and $x$ is a general input function with land, labor, and cow arguments. In reality, many more inputs affect output. On the other hand, data limitations preclude the inclusion of more inputs such as feed or genetic quality. 
Table 1. Inputs and outputs used in the data envelopment analysis models ${ }^{1}$

\begin{tabular}{|c|c|c|c|c|c|c|c|}
\hline DMU & $\begin{array}{l}\text { Labor } \\
\text { (FTE) }\end{array}$ & Cows & $\begin{array}{l}\text { Land } \\
\text { (ha) }\end{array}$ & $\begin{array}{c}\text { Milk } \\
\text { production } \\
(\mathrm{kg} / \mathrm{cow})\end{array}$ & $\begin{array}{c}\text { Butterfat } \\
\text { production } \\
\text { (kg/cow) }\end{array}$ & $\begin{array}{c}\text { Debt } \\
(\$)\end{array}$ & $\underset{\substack{\text { Net } \\
\text { income } \\
(\$)}}{ }$ \\
\hline 1 & 2.66 & 70 & 98 & 10,490 & 372 & 0 & 15,186 \\
\hline 2 & 3.06 & 67 & 97 & 8,736 & 337 & 0 & 40,838 \\
\hline 3 & 3.59 & 72 & 38 & 8,267 & 319 & 70,769 & 26,630 \\
\hline 4 & 1.00 & 60 & 48 & 10,010 & 392 & 140,627 & 49,149 \\
\hline 5 & 2.80 & 180 & 166 & 8,918 & 330 & 0 & 78,718 \\
\hline 6 & 2.00 & 112 & 66 & 9,953 & 359 & 18,005 & 85,055 \\
\hline 7 & 1.60 & 40 & 109 & 7,446 & 302 & 0 & 19,226 \\
\hline 8 & 2.28 & 55 & 105 & 9,362 & 337 & 0 & 44,055 \\
\hline 9 & 4.71 & 118 & 121 & 9,016 & 347 & 171,277 & 28,996 \\
\hline 10 & 1.80 & 55 & 19 & 9,067 & 317 & 120,473 & 19,756 \\
\hline 11 & 2.00 & 58 & 57 & 8,605 & 339 & 205,506 & 31,365 \\
\hline 12 & 2.00 & 87 & 63 & 9,148 & 336 & 179,000 & 68,797 \\
\hline 13 & 1.80 & 40 & 36 & 6,802 & 262 & 6,939 & 13,352 \\
\hline 14 & 2.00 & 53 & 136 & 8,433 & 298 & 24,809 & 16,982 \\
\hline 15 & 4.18 & 249 & 257 & 7,339 & 294 & 556,447 & 121,596 \\
\hline 16 & 1.60 & 43 & 40 & 8,530 & 303 & 104,729 & 42,544 \\
\hline 17 & 1.38 & 55 & 101 & 6,795 & 256 & 30,971 & 49,162 \\
\hline 18 & 1.60 & 36 & 85 & 4,870 & 183 & 31,931 & 138 \\
\hline 19 & 1.90 & 44 & 60 & 7,426 & 297 & 17,646 & 44,342 \\
\hline 20 & 1.51 & 54 & 81 & 8,350 & 315 & 118,951 & 76,682 \\
\hline 21 & 1.00 & 98 & 121 & 9,406 & 365 & 87,517 & 6,057 \\
\hline 22 & 1.65 & 36 & 89 & 7,166 & 267 & 16,639 & 9,443 \\
\hline 23 & 1.67 & 54 & 147 & 4,391 & 155 & 0 & 18,397 \\
\hline 24 & 3.20 & 110 & 127 & 9,981 & 349 & 0 & 118,858 \\
\hline 25 & 1.00 & 64 & 51 & 11,438 & 405 & 178,839 & 89,216 \\
\hline 26 & 3.72 & 110 & 42 & 8,995 & 352 & 384,223 & 81,825 \\
\hline 27 & 1.93 & 81 & 80 & 11,201 & 410 & 111,901 & 92,366 \\
\hline 28 & 2.17 & 56 & 74 & 7,015 & 267 & 49,777 & 33,510 \\
\hline 29 & 2.00 & 71 & 61 & 6,689 & 254 & 16,232 & 66,026 \\
\hline 30 & 1.00 & 30 & 45 & 6,105 & 245 & 13,065 & 4,206 \\
\hline 31 & 2.00 & 82 & 52 & 5,379 & 202 & 25,487 & 0 \\
\hline 32 & 2.00 & 73 & 113 & 7,844 & 278 & 28,563 & 41,272 \\
\hline 33 & 3.00 & 143 & 126 & 9,045 & 353 & 112,180 & 97,610 \\
\hline 34 & 1.15 & 62 & 86 & 8,621 & 322 & 0 & 27,844 \\
\hline Mean & 2.15 & 77 & 88 & 8,260 & 309 & 83,015 & 45,859 \\
\hline SD & 0.92 & 45 & 47 & 1,657 & 59 & 118,534 & 34,298 \\
\hline Minimum & 1.00 & 30 & 19 & 4,391 & 155 & 0 & 0 \\
\hline Maximum & 4.71 & 249 & 257 & 11,438 & 410 & 556,447 & 121,596 \\
\hline
\end{tabular}

${ }^{1} \mathrm{DMU}=$ decision-making unit (i.e., dairy farm); FTE = full-time equivalent.

Farm Bureau tax records from 349 Pennsylvania dairy farms for 2001 were used for analysis. Farms in the sample had $\geq 20$ cows and generated at least half of their gross farm receipts from milk sales (Roth and Hyde, 2001). The data were stratified to control for breed, milking barn setup, and milking system. This resulted in a data set of $34 \mathrm{DMU}$ consisting solely of Holstein herds using stanchion barns and operating pipeline milking systems. It should be noted that DEA is often applied to far fewer DMU (Ragsdale, 2007). Because DEA is nonparametric, statistical hypothesis testing is not possible. Most likely, a large number of data points (i.e., DMU) will increase the computational burden because a linear program must be solved for each DMU in the sample.

Due to the structure of the data set it was not possible to determine whether all resources such as land or labor were utilized by the dairy operation. Excess resources will be identified in the analysis as surpluses. Because DEA is a nonparametric method, the relatively few farms in the data set are not a concern in a statistical sense. That is, the DEA approach is not a statistical approach from which tests of significance are conducted and therefore, degrees of freedom issues associated with 34 observations are not an issue. Input and output data and summary statistics are shown in Table 1, as well as 1 additional economic input (dollars of debt capital used) and 1 additional economic output (dollars of net income) to be discussed later in the paper.

\section{RESULTS AND DISCUSSION}

The DEA results are presented in Table 2. As shown, 6 out of the 34 DMU were identified as DEA-efficient. That is, 6 dairy farms have no input or output inefficiencies, thereby having DEA efficiency scores equal to 
Table 2. Results of the technical data envelopment analysis (DEA) model, decision-making units (DMU; i.e., dairy farm) ranked by efficiency scores with slacks ${ }^{1}$ for labor and land and target and actual milk and butterfat production

\begin{tabular}{|c|c|c|c|c|c|c|c|}
\hline DMU & Efficiency & $\begin{array}{l}\text { Slack labor } \\
\text { (full-time } \\
\text { equivalent) }\end{array}$ & $\begin{array}{l}\text { Slack land } \\
\text { (ha) }\end{array}$ & $\begin{array}{l}\text { Actual milk } \\
\text { production } \\
\text { (kg/cow) }\end{array}$ & $\begin{array}{l}\text { Target milk } \\
\text { production } \\
\text { (kg/cow) }\end{array}$ & $\begin{array}{c}\text { Actual } \\
\text { butterfat } \\
\text { production } \\
(\mathrm{kg})\end{array}$ & $\begin{array}{c}\text { Target } \\
\text { butterfat } \\
\text { production } \\
(\mathrm{kg})\end{array}$ \\
\hline 6 & 1.0000 & $-^{2}$ & - & 9,953 & - & 359 & - \\
\hline 10 & 1.0000 & - & - & 9,067 & - & 317 & - \\
\hline 21 & 1.0000 & - & - & 9,406 & - & 365 & - \\
\hline 25 & 1.0000 & - & - & 11,438 & - & 405 & - \\
\hline 26 & 1.0000 & - & - & 8,995 & - & 352 & - \\
\hline 27 & 1.0000 & - & - & 11,201 & - & 410 & - \\
\hline 4 & 0.9688 & 0.0470 & - & 10,010 & 11,431 & 392 & 405 \\
\hline 1 & 0.9187 & 1.3970 & 38.0763 & 10,490 & 11,418 & 372 & 405 \\
\hline 24 & 0.8726 & 1.2925 & 35.3607 & 9,981 & 11,438 & 349 & 405 \\
\hline 33 & 0.8660 & 0.1756 & - & 9,045 & 11,325 & 353 & 407 \\
\hline 3 & 0.8585 & 1.4121 & - & 8,267 & 9,915 & 319 & 372 \\
\hline 9 & 0.8467 & 1.5998 & 4.4579 & 9,016 & 11,201 & 347 & 410 \\
\hline 12 & 0.8455 & 0.3450 & - & 9,148 & 11,078 & 336 & 397 \\
\hline 11 & 0.8274 & 0.5245 & - & 8,605 & 11,210 & 339 & 410 \\
\hline 8 & 0.8271 & 0.9863 & 46.6068 & 9,362 & 11,318 & 337 & 407 \\
\hline 2 & 0.8225 & 1.2036 & 25.6409 & 8,736 & 11,201 & 337 & 410 \\
\hline 5 & 0.8160 & - & 18.4496 & 8,918 & 11,412 & 330 & 404 \\
\hline 34 & 0.7929 & - & 26.1823 & 8,621 & 11,356 & 322 & 407 \\
\hline 20 & 0.7678 & 0.1691 & 21.6433 & 8,350 & 11,201 & 315 & 410 \\
\hline 16 & 0.7471 & 0.6709 & 3.7076 & 8,530 & 11,418 & 303 & 405 \\
\hline 14 & 0.7373 & 0.8640 & 69.0549 & 8,433 & 11,438 & 298 & 405 \\
\hline 7 & 0.7356 & 0.4747 & 51.1073 & 7,446 & 11,201 & 302 & 410 \\
\hline 19 & 0.7246 & 0.6158 & 12.3096 & 7,426 & 11,201 & 297 & 410 \\
\hline 15 & 0.7238 & - & 38.8779 & 7,339 & 11,404 & 294 & 406 \\
\hline 32 & 0.6858 & 0.5894 & 38.1310 & 7,844 & 11,438 & 278 & 405 \\
\hline 22 & 0.6502 & 0.5131 & 34.5807 & 7,166 & 11,201 & 267 & 410 \\
\hline 28 & 0.6502 & 0.5397 & 12.5756 & 7,015 & 11,201 & 267 & 410 \\
\hline 13 & 0.6418 & 0.6230 & - & 6,802 & 11,291 & 262 & 408 \\
\hline 29 & 0.6252 & 0.4349 & - & 6,689 & 11,359 & 254 & 407 \\
\hline 17 & 0.6248 & 0.0441 & 29.1322 & 6,795 & 11,201 & 256 & 410 \\
\hline 30 & 0.5986 & 0.1700 & 8.9709 & 6,105 & 11,201 & 245 & 410 \\
\hline 31 & 0.5253 & 0.0852 & - & 5,379 & 10,525 & 202 & 385 \\
\hline 18 & 0.4455 & 0.3300 & 22.0682 & 4,870 & 11,201 & 183 & 410 \\
\hline 23 & 0.3839 & 0.3159 & 40.1557 & 4,391 & 11,438 & 155 & 405 \\
\hline
\end{tabular}

${ }^{1}$ Slack indicates the amount by which a DEA model constraint is not satisfied with equality and therefore, represents the amount by which an input is overused relative to how efficient producers use the input.

${ }^{2}$ Indicates no surplus labor or land (in the slack labor and land columns), and indicates that the target milk or butterfat production is equal to actual milk or butterfat production (in the milk and butterfat columns).

1. These 6 dairy farms define the efficient frontier and represent the best practice farms for combining land, labor, and cows to produce milk and butterfat. These efficient dairies average 1.91 labor FTE, 87 cows, and use 156 ha to produce $10,010 \mathrm{~kg} / \mathrm{cow}$ of milk and 368 $\mathrm{kg} / \mathrm{cow}$ of butterfat.

The DEA efficiency scores, slack labor, land, and target milk and butterfat production for the inefficient dairy farms are presented in Table 2 . A slack value indicates the amount by which a DEA model constraint is not satisfied with equality and therefore, represents the amount by which an input is overused relative to how the most efficient producers use the input. Inefficient dairies average 2.16 labor FTE, 77 cows, and use 102 ha to produce $7,300 \mathrm{~kg} / \mathrm{cow}$ of milk and $275 \mathrm{~kg} / \mathrm{cow}$ of butterfat. The average target level of inputs for this group is $1.21 \mathrm{FTE}, 61$ cows, and 57 ha to produce 9,900 $\mathrm{kg} / \mathrm{cow}$ of milk and $359 \mathrm{~kg} / \mathrm{cow}$ of butterfat. In all instances cows were used at an efficient level, meaning there was no slack in the cow inputs; thus, the cow input is not reported in Table 2.

For the inefficient dairy farms, in most cases labor and land were far in excess of the requirements of the system to achieve an efficient level of production. On average, labor was in excess by 0.62 FTE per farm (range 0 to $1.5998 \mathrm{FTE}$ ) and land was in excess by 28.85 ha (range 0 to 69.05 ha).

Data envelopment analysis also allows a DMU to identify how to change the input mix to achieve an efficient level of production for the farming system under review. As an example of how to interpret the results to achieve this level we used DMU 4 (the least 
inefficient DMU) as an example. This DMU had a DEA efficiency score of 0.9688 indicating that this farm should decrease its use of land, labor, and cows by $3.12 \%$ (i.e., $1-0.9688$ ) as a first step toward becoming DEA efficient. Alternatively, DMU 4 should be able to achieve its current level of production using $96.9 \%$ of its current input levels. However, as indicated in Table 2, 2 subsequent steps for complete DEA efficiency are required. First, labor use should be further adjusted downward by 0.047 FTE as indicated by the slack labor column. Second, milk and butterfat production should both be increased. Milk production should increase from $10,010 \mathrm{~kg} / \mathrm{cow}$ (Table 1) to $11,431 \mathrm{~kg} / \mathrm{cow}$, and butterfat production, which should increase from 392 to $405 \mathrm{~kg}$, in percentage terms would actually decrease from 3.92 to $3.54 \%$. The percentage declines because of the increase in milk production reported. In more general terms, the DEA results suggest that for DMU 4, milk and butterfat production should be raised relative to current levels and the target levels of production should be obtainable with the use of less land, labor, and cows as indicated.

As another example, DMU 23 is the least efficient dairy farm in the sample with a DEA score of 0.3839 . Therefore, adjusting all input levels to about $38 \%$, or reducing inputs by $62 \%$, of the levels currently used on the farm is a first step toward efficient milk and butterfat production. After these reductions, the farm should be capable of producing $11,438 \mathrm{~kg} / \mathrm{cow}$ of milk after further reducing labor use by $0.32 \mathrm{FTE}$ and land use by about 40 ha. For this farm, butterfat production is already at a level consistent with efficiency and hence no further adjustments are necessary. In these 2 cases and in all other cases where inefficiencies were identified the challenge for producers is to change the level of inputs or outputs to achieve the efficient levels of production, which may not be easy, especially in the case of inputs such as land.

Benchmarking is another important way for inefficient DMU to improve their situation. Yet, the question of what level of inputs or outputs to benchmark to is an open question. For example, the average level of milk production for the $34 \mathrm{DMU}$ in the sample is 8,260 $\mathrm{kg} / \mathrm{cow}$. Benchmarking to this average is not unlike benchmarking to the state average or some other average. The DEA technique suggests a different way of benchmarking by actually identifying the efficient DMU that each inefficient DMU should use as a benchmark. When a set of benchmarks is identified for an inefficient producer, it may be possible for the producer to study these benchmarks to determine if changes can be made to the production systems to achieve the efficiency targets estimated.
Table 3. Benchmark decision-making unit (DMU; i.e., dairy farm) and returns to scale for the inefficient DMU from the technical model ranked by efficiency score

\begin{tabular}{|c|c|c|c|}
\hline Rank & DMU & $\begin{array}{l}\text { Benchmark } \\
\text { \#1 DMU }\end{array}$ & $\begin{array}{c}\text { Benchmark } \\
\text { \#2 DMU }\end{array}$ \\
\hline 7 & 4 & 25 & 27 \\
\hline 8 & 1 & 25 & 27 \\
\hline 9 & 24 & 25 & \\
\hline 10 & 33 & 25 & 27 \\
\hline 11 & 3 & 25 & 26 \\
\hline 12 & 9 & 27 & \\
\hline 13 & 12 & 25 & 26 \\
\hline 14 & 11 & 25 & 27 \\
\hline 15 & 8 & 25 & 27 \\
\hline 16 & 2 & 27 & \\
\hline 17 & 5 & 21 & 25 \\
\hline 18 & 34 & 25 & 27 \\
\hline 19 & 20 & 27 & \\
\hline 20 & 16 & 25 & 27 \\
\hline 21 & 14 & 25 & \\
\hline 22 & 7 & 27 & \\
\hline 23 & 19 & 27 & \\
\hline 24 & 15 & 25 & 27 \\
\hline 25 & 32 & 25 & \\
\hline 26 & 22 & 27 & \\
\hline 27 & 28 & 27 & \\
\hline 28 & 13 & 25 & 27 \\
\hline 29 & 29 & 25 & 27 \\
\hline 30 & 17 & 27 & \\
\hline 31 & 30 & 27 & \\
\hline 32 & 31 & 25 & 26 \\
\hline 33 & 18 & 27 & \\
\hline 34 & 23 & 25 & \\
\hline
\end{tabular}

Presented in Table 3 are the top 2 benchmarks for each inefficient DMU listed in Table 2. Using DMU 4 as an example again shows that DMU 25 is the dairy farm that DMU 4 should emulate. Decision-making unit 4 is a 60 -cow dairy that is using $1 \mathrm{FTE}$ of labor and $48 \mathrm{ha}$ of land to produce $10,010 \mathrm{~kg} / \mathrm{cow}$ of milk and $392 \mathrm{~kg} / \mathrm{cow}$ of butterfat, whereas DMU 25 is a 64 -cow dairy using 1 FTE of labor and 51 ha of land to more efficiently produce $11,438 \mathrm{~kg} / \mathrm{cow}$ of milk and $405 \mathrm{~kg} /$ cow of butterfat. Clearly, benchmarking to the group average of $8,260 \mathrm{~kg} / \mathrm{cow}$ of milk is too low a target for DMU 4 and will not resolve their production inefficiency. Other benchmarks in Table 3 are interpreted similarly.

An extension to the basic production-oriented model presented in the previous section was developed by including 1 additional economic input and 1 additional economic output. Dollars of debt capital is an important input for most dairy farms because modern dairy production is very capital intensive. The use of this input has important business management implications in that debt capital is an inexpensive way to finance business growth because it is generally less expensive than equity capital. The use of debt capital can accelerate the rate of growth in equity capital, but this accelerated growth comes at the expense of the farm's risk position 
Table 4. Results of the economic data envelopment analysis model, decision-making units (DMU; i.e., dairy farms) ranked by efficiency scores with slacks ${ }^{1}$ for labor, land, and debt, and target and actual milk and butterfat production

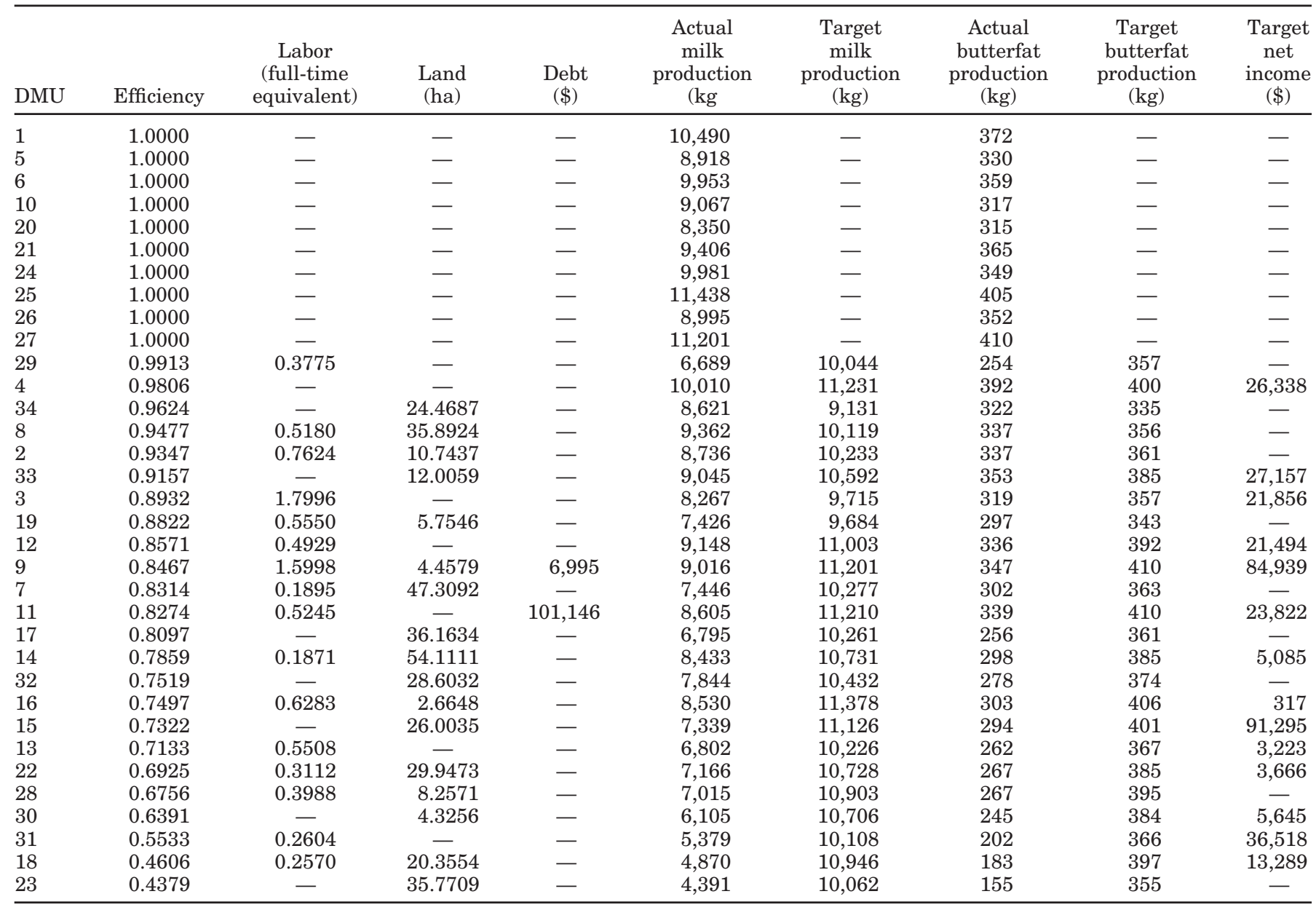

${ }^{1}$ Slack indicates the amount by which a DEA model constraint is not satisfied with equality and therefore, represents the amount by which an input is overused relative to how efficient producers use the input.

because greater debt capital use generally increases the risk of equity loss. Therefore, it seems reasonable that an efficient if not optimal level of debt capital is preferable.

The additional output variable included in the model is dollars of net income. In contrast to milk and butterfat production, net income efficiency is influenced by effective business management of costs, and perhaps price risk, as well as production efficiency. Here, milk pricing and the effective use of capital including machinery is accounted for when measuring DEA efficiency. The resulting DEA model is the CCR model outlined in Eq. 1, where inputs and outputs are now generally specified as

$$
\begin{gathered}
\left.y^{\prime} \text { (milk, butterfat, net income }\right)= \\
x^{\prime} \text { (land, labor, cows, debt capital). }
\end{gathered}
$$

The results from the DEA model with production and economic inputs and outputs are presented in Table 4. The first thing to notice is that all the efficient DMU from the previous model are included in the efficient set for this model. This is to be expected, because the only change to the model is the addition of 2 extra dimensions. Hence, producers that were efficient in the first model are still on the frontier with respect to the original input and output variables and therefore still efficient. Nevertheless, with the additional input and output variables, the dimensions of the frontier increase 2 -fold, and more DMU are identified as being efficient.

The addition of the new variables changes the relative rankings, slack resources, target levels of production, and benchmarks of the inefficient DMU. For example, DMU 29 had an efficiency score of 0.6252 in the production-oriented model and slack labor of 0.4349 
FTE. In the economic model, the efficiency of this DMU is now 0.9913 with slightly less slack labor. This large difference highlights the effect of economic information on estimates of DEA efficiency. By changing the nature of the efficient frontier by including economic information, a dairy farm that is very inefficient with respect to production may be much less inefficient from an economic perspective. Superior business management skills are the likely cause of DMU 29 being much closer to the new efficient frontier because this farm makes efficient use of debt capital and generates an efficient level of net income relative to the other DMU.

For DMU 29, the target level of milk production is now $10,044 \mathrm{~kg} / \mathrm{cow}$, down from $11,359 \mathrm{~kg} / \mathrm{cow}$ in the production model. Similar levels of reduction were observed for butterfat production down from 407 to 357 $\mathrm{kg} / \mathrm{cow}$. The benchmark group for this producer changed from the previous model. The production-oriented benchmark producers were DMU 25 and 27, whereas in the economic model, the benchmark group now consists of DMU 6, 24, and 25.

As another example, DMU 11 has the same efficiency score in both models, indicating that this dairy farm is no further from or closer to the new frontier. But, as shown in Table 4, DMU 11 has a high amount of slack debt capital and net income. In addition to using about $17 \%$ less of all inputs, DMU 11 would have to use about $\$ 100,000$ less debt capital and generate about $\$ 24,000$ more net income to be DEA-efficient. This result is not surprising given that the reason net income is too low is simply that the farm has too much debt capital and is seeing much of its profitability leave the farm as interest expense. In fact, the slack net income of $\$ 23,822$ expressed relative to the farm's debt capital of $\$ 205,506$ is $11.6 \%$, which likely approximates DMU 11 's cost of debt capital. Decision-making unit 11 is actually a profitable dairy, but much of its profitability is being enjoyed by its creditor.

\section{CONCLUSIONS}

Data envelopment analysis is used to examine the production and economic efficiency of a sample of Pennsylvania dairy farms. The technique is nonparametric and capable of handling multiple outputs as well as multiple inputs. The results generally indicate that overall input inefficiency and in some cases, more specific input and output inefficiencies can be readily identified for dairy farms. Too much labor use and an overinvestment in land in conjunction with too little milk and butterfat production characterize inefficient dairy producers. When considering economic inputs and outputs, the overuse of debt capital is identified as one possible way for dairy farms to be inefficient. The technique provides information regarding the specific way a given inefficient dairy farm can become efficient. Lastly, the approach has merit for assisting in the identification of appropriate benchmarks for inefficient producers to emulate. This information provides a more meaningful goal for a producer to aim for compared with, for example, a state average.

\section{REFERENCES}

Bravo-Ureta, B. E., and L. Rieger. 1991. Dairy farm efficiency measurement using stochastic frontiers and neoclassical duality. Am. J. Agric. Econ. 73:421-428.

Charnes, A., W. W. Cooper, and E. Rhodes. 1978. Measuring the efficiency of decision-making units. Eur. J. Oper. Res. 2:429-444.

Cooper, W. W., L. M. Seiford, and K. Tone. 2000. Data envelopment analysis: A comprehensive text with models, applications, references and DEA-Solver software. Kluwer Academic Publishers, Boston, MA.

Fraser, I., and D. Cordina. 1999. An application of data envelopment analysis to irrigated dairy farms in Northern Victoria, Australia. Agric. Syst. 59:267-282.

Fraser, I., and P. Hone. 2001. Farm-level efficiency and productivity measurement using panel data: Wool production in southwest Victoria. Aust. J. Agric. Res. Econ. 45:215-232.

Jaforullah, M., and E. Premachandra. 2004. Sensitivity of technical efficiency estimates to estimation approaches: An investigation using New Zealand dairy industry data. Paper presented to the Asia-Pacific Productivity Conference, Brisbane, Australia.

Jaforullah, M., and J. Whiteman. 1999. Scale efficiency in the New Zealand dairy industry: A non-parametric approach. Aust. J. Agric. Res. Econ. 43:523-541.

Ragsdale, C. 2007. Spreadsheet modeling and decision analysis, South-Western College Publishing, Cincinnati, OH.

Roth, S., and J. Hyde. 2001. 2000 Pennsylvania Dairy Farm Business Analysis. Department of Agricultural Economics and Rural Sociology, Pennsylvania State Univ., University Park.

Seitz, W. 1971. Productive efficiency in the steam-electric generating industry. J. Polit. Econ. 79:878-886.

Tauer, L. W. 1993. Short-run and long-run efficiencies of New York dairy farms. Agric. Res. Econ. Rev. 22:1-9.

Tauer, L. W. 2001. Efficiency and competitiveness of the small New York dairy farm. J. Dairy Sci. 84:2573-2576.

Weersink, A., C. G. Turvey, and A. Godah. 1990. Decomposition measures of technical efficiency for Ontario dairy farms. Can. J. Agric. Econ. 38:439-456. 